\title{
A Comparative 3D Finite Element Computational Study of Stress Distribution and Stress Transfer in Small-Diameter Conical Dental Implants
}

\author{
Onur Can KALAY, Hasan KARAMAN, Fatih KARPAT*, Oğuz DOĞAN, Celalettin YÜCE, Esin KARPAT, Lokesh DHANASEKARAN, \\ Morshed KHANDAKER
}

\begin{abstract}
The implant design is one of the main factors in implant stability because it affects the contact area between the bone and the implant surface and the stressstrain distribution at the bone-implant interface. In this study, the effect of different groove geometries on stress-strain distributions in small-diameter conical implants is investigated using the finite element method (FEM). Four different thread models (rectangular, buttressed, reverse buttressed, and symmetrical profile) are created by changing the groove geometry on the one-piece implants, and the obtained results are compared. The stress shielding effect is investigated through the dimensionless numbers that characterize the load-sharing between the bone-implant. It is determined that the lowest stress distribution is observed with rectangular profiled groove geometry. Besides, it is obtained that the buttressed groove geometry minimizes the stress effects transmitted to the periphery of the implant. The symmetrical profiles had better performance than rectangular profiles in stress transfer.
\end{abstract}

Keywords: finite element method; groove geometry; implant; implant design

\section{INTRODUCTION}

Dental implants are artificial roots that are in the form of a tooth root and are usually made of titanium material instead of natural teeth that have been damaged or unfulfilled. In dental applications, the implants are placed in the jawbone, which is composed of the trabecular, boneouter cortical layer of different densities. Although the success rate of implants has increased to $97 \%$ in recent years, some problems arise due to inadequate bone quality, improper implant positioning and design, loss of implant integration $[1,2]$.

In the success of implantation, the formation of strong bonds between the bone tissue and the load-bearing surface of the implant, which is described as "osseointegration", is an important parameter. Branemark [3] has defined the osseointegration as a direct structural and functional connection between live bone tissue and titanium implant material. If the osseointegration cannot be achieved adequately, the implant is loosened, and damage occurs [4]. The bond between the implant and the bone tissue is directly related to the implant material, implant design, surface roughness, and topography.

Since dental implants function by transferring forces to surrounding tissues, their design is also crucial for the health of the implant application. Implants with nongrooved, flat, and smooth surfaces result in shear forces, while grooved implants increase the contact area between bone tissue and implant. Moreover, grooved implants are more suitable geometries due to force distribution [5].

In dental implants, four different groove geometries are used: symmetrical (V type), buttressed, reverse buttressed, and rectangular profile [6]. The groove shape is critical for the transfer of the stimulants, which under bone balance and occlusal loads, from implant to bone [7]. Baggi et al. [8] examined the groove design characteristics and found less bone damage under high contact areas.

Another critical problem encountered in dental implant applications is stress shielding. This unfavourable condition is less observed in titanium alloys, which are the most commonly used implant materials in dental implant applications [9]. However, bone loss may occur on the surrounding bone around the implant because the forces within the physiological limits necessary to maintain bone health cannot be transmitted in the long-term. Therefore, stress shielding effects should not be underestimated in the dental implant design.

The stability of dental implants is directly related to bone remodelling between the bone and the implant surface. The reaction of bone to the load-sharing between the bone and implant develops according to Wolff's law [10]. According to Wolff's law, mechanical stress has a response to the bone. With the application of the load, a negative potential is created on the bone under pressure, and bone formation is stimulated. That is, where stress is reduced, bone resorption by the old bone cell is observed, while the immature bone cell in the area of increased stress promotes new bone formation.

Loading conditions must be chosen in accordance with the clinical point of view, taking into account patient diversity for successful engineering. The magnitude of the bite force may vary due to age, nutrition history, gender, and eating habits. In this regard, it should be noted that varying forces could result in different stress concentrations. The bite force increases with age and growth in childhood, then remains fairly constant from around age 20 to 40 or 50, then declines. Many studies show that the maximum bite force is higher in males than in females [11]. Gavião et al. [12] studied the bite force of fifteen children of both genders with good systemic and oral health. The children chewed a standardized silicon tablet, and the bite force was measured with a pressurized transmitter tube. The study found the mean bite force value was 235,12 N. Palinkas et al. [13] examined the maximum bite force of individuals aged 7 to 80 from both genders with a sample of 177 subjects. Five groups were determined depending on individuals' age. It was observed that the highest value was $339 \pm 28 \mathrm{~N}$ in the adolescent group (13 - 20 years old) and the lowest value was $177 \pm$ $16 \mathrm{~N}$ in children ( 7 - 12 years old) when the maximal bite force values measured in the right molar region were examined. Besides, the bite force under the same conditions was found to be $280 \pm 24 \mathrm{~N}$ and $263 \pm 20 \mathrm{~N}$ for young adults $(21-40$ years old) and adults $(41-60$ years 
old), respectively. As a result, using a wide loading range is significant for compatibility with the clinical perspective, considering patient diversity (i.e., age, gender, parafunctional habits, and from anterior to posterior in the same mouth, etc.). Molars are teeth located at the rear end of the mouth, which contribute to food grinding. They are the only teeth that can withstand $300 \mathrm{~N}$ maximum force [14]. Therefore, dental implants placed in the molar region are frequently examined in finite element computational studies in the literature.

It is imperative to understand the process of bone remodelling in implant design and material selection. With the change in implant design, the resistance of the geometry may increase. As a result of stress shielding, a decrease in stress transmission of the implant to around the circumference is concerned. Thus, bone loss may occur in the long-term because the forces within the physiological limits required to maintain bone health cannot be transmitted [15].

Gefen [16] investigated the effect of different groove geometries on stress shielding and used dimensionless numbers to characterize stress transfer. Haase and Rouhi [17] compared the effects of mechanical stimulants, stress, and strain energy intensity on stress shielding when implant parameters (implant diameter, groove geometry, implant size, etc.) are changed. The study also used the dimensionless number to describe the stress shielding that prevents the transfer of stress and strain required for bone regeneration.

This study used a small-diameter one-piece implant since the standard implant diameters range from 3,75 to 4,1 $\mathrm{mm}$ [18]. The small-diameter implants may be exposed to an increased risk of fractures due to prosthetic components and small diameters that can cause bone overload [19]. However, some studies have reported positive results for the small-diameter implants [20]. The small-diameter implants have found extensive use, considering factors such as alveolar width, etc. Clinically reported success rates of small-diameter implants are more than $95 \%$ at 11 years following the implant application [21]. Besides, onepiece implants are asserted to demonstrate minimal absorption of the peri-implant bone through the absence of a micro-gap related with the micro-leakage and bacterial contamination [22].

Balkin et al. [23] reported that small-diameter implants give similar osseointegration values to large-diameter implants. However, since small-diameter implants have less surface area, they can produce different stress-strain transfer parameters according to standard implants and endanger the support provided by the surrounding bone [24]. Moreover, the studies show that the implant's fracture resistance is reduced by $50 \%$ by decreasing the standard implant diameter by $20 \%$ [25]. Besides, the use of angled teeth in small-diameter implants increases the transfer of the stimulus (stress, energy density, strain, etc.).

In this study, the effects of different groove geometries in small-diameter conical implants on stress and strain changes on alveolar bone and implant are investigated by the finite element method (FEM). Thus, the effect of groove geometry on stress shielding is examined via the stress transfer parameter. The stress transfer required for bone regeneration is evaluated through non-dimensional numbers that characterize the load-sharing between the bone-implant interface for different groove geometries. Hence, considering the bone loss that may occur on the peripheral bone, it is aimed to investigate which groove profile is superior for small-diameter implants.

\section{MATERIALS AND METHODS}

The one-piece small-diameter conical screw implants and bone layers are modelled in SolidWorks ${ }^{\circledR}$ (Dassault Systemes, Waltham, MA, USA) design software. The cortical bone layer is $2 \mathrm{~mm}$ thick [26], and the trabecular bone layer is modelled as $32 \mathrm{~mm} \times 28 \mathrm{~mm} \times 25 \mathrm{~mm}$. The implant models with titanium material are based on the Nobel Biocare ${ }^{\circledR}$ (NobelDirect Groovy NP, Gothenburg, Sweden) 2015-2016 product catalogue [27]. The diameter and length of the implant are determined as 3,5 $\mathrm{mm}$ and 13 $\mathrm{mm}$, respectively. The dental crown features are ignored, and the model is formed as one-piece [22]. As a pitch length, $0,6 \mathrm{~mm}$ is selected, which is the most widely used commercially (Fig. 1).

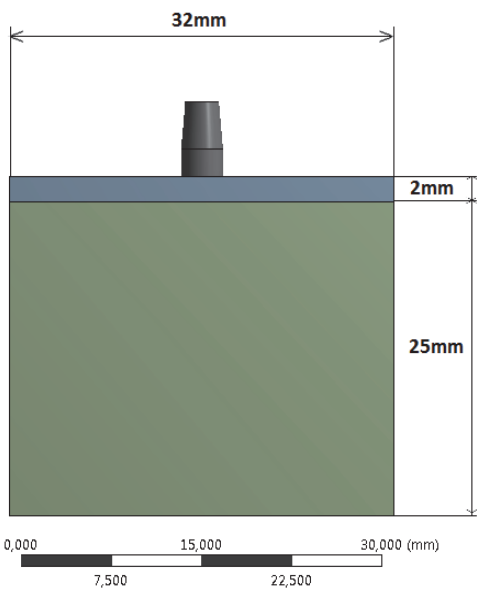

(a)

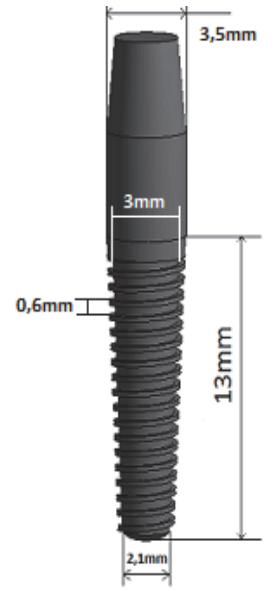

(b)
Figure 1 (a) Cortical and trabecular bone (b) implant dimensions

This study investigated rectangular $\left(q_{1}=q_{2}=90^{\circ}\right)$, symmetrical $\left(q_{1}=q_{2}=15^{\circ}\right)$, buttressed $\left(q_{1}=5^{\circ}, q_{2}=20^{\circ}\right)$, and reverse buttressed $\left(q_{1}=20^{\circ}, q_{2}=5^{\circ}\right)$ groove geometries (Fig. 2). The groove width is kept constant at $0,4 \mathrm{~mm}$ for all groove geometries. Tooth width and tooth height are chosen as $0,2 \mathrm{~mm}$ and $0,25 \mathrm{~mm}$, respectively, in all geometries. The height of the tooth section is determined as $12,1 \mathrm{~mm}$, and the largest diameter is $3,5 \mathrm{~mm}$. The largest diameter on the tooth portion is $3 \mathrm{~mm}$, whereas the smallest diameter is $2,1 \mathrm{~mm}$.

Thus, the finite element model is created, and boundary conditions are determined by transferring the implant geometries to ANSYS ${ }^{\circledR} 16.1$ (Canonsburg, PA, USA) Workbench (Fig. 3). A proper definition of the contact model between bone and implant is clinically important. The micro-motions and osseointegration complicate the connection form between the implant and the surrounding bone at the interface. In this regard, some studies in the literature assume that the bone-implant interface is $100 \%$ bonded or fully osseointegrated [28]. In contrast, others defined a friction coefficient between the bone and implant interface [29]. Defining the bone-implant interface as fully osseointegrated may cause a decrease in bone displacement and stress values. Besides, this is not 
suitable for modeling from a clinical point of view. In reality, most implant systems have micro-motions at the bone-implant interface. Jamadagni et al. [29] obtained the average friction coefficient between titanium and the bone
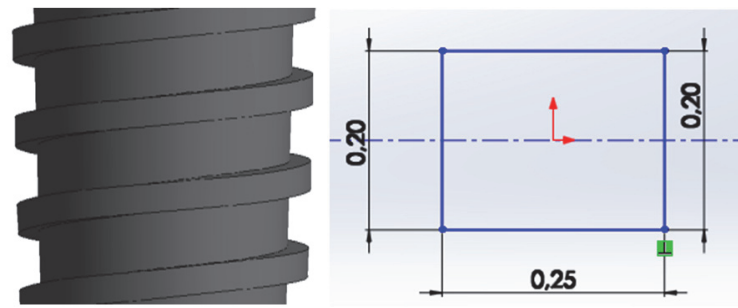

(a)
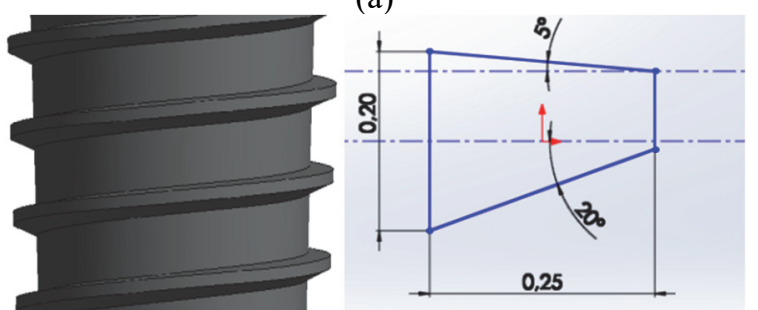

(c)

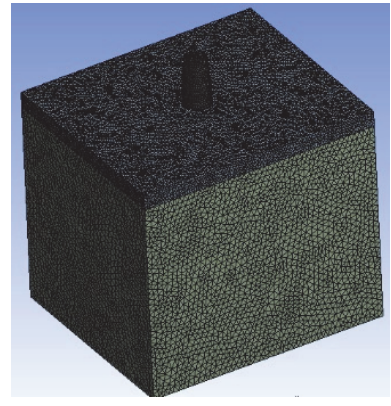

(a)

Figure 2 Groove geometries and dimensions

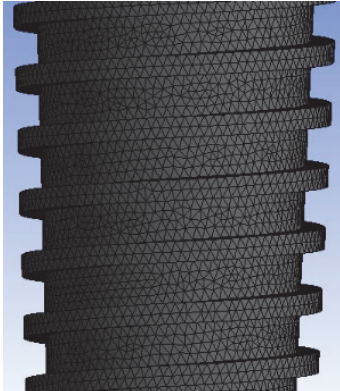

(b) as 0,5 using finite element analysis for a dental implant application. As a result, this study defined a friction coefficient of 0,5 to the bone-implant interface, considering the bone and implant micro-motions.
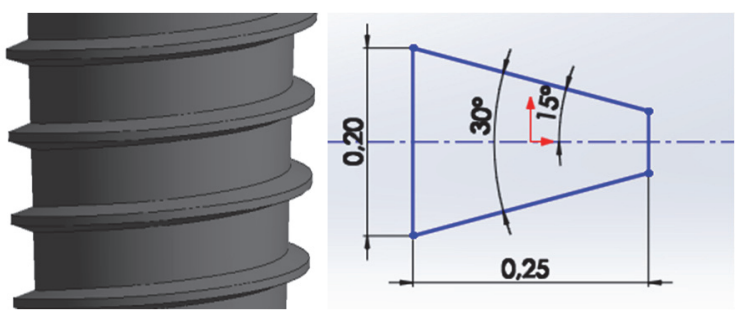

(b)
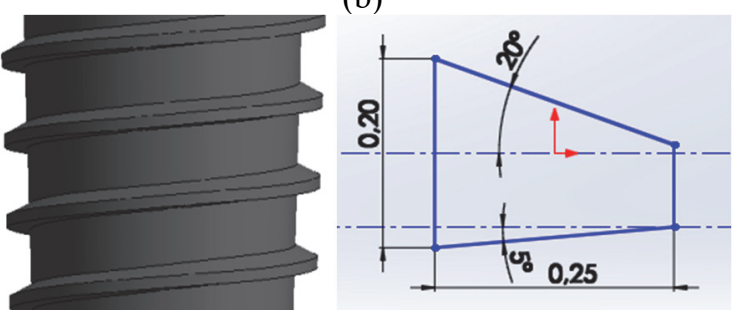

(d)

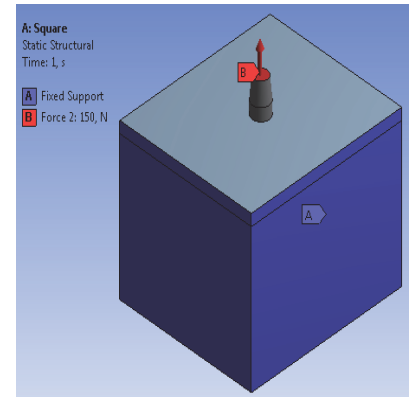

(c)
This study performed static structural analysis via ANSYS $^{\circledR} 16.1$ software. Three-dimensional tetrahedral mesh elements with four nodes and four faces are used according to geometry. The $0,3 \mathrm{~mm}$ element size is used for the trabecular bone and $0,3 \mathrm{~mm}$ cortical layers for the implant. Besides, a surface element (face-size) of $0,1 \mathrm{~mm}$ is assigned for all surfaces of the implant-corticaltrabecular interfaces as a local element size. The mesh quality is checked before the simulations considering that the mesh structure preferred can affect the accuracy of the results obtained [30].

The mesh quality used in 3D finite element simulations is evaluated with the general quality indicators. It is determined that the maximum skewness value of the mesh is below 0,95 , and the average skewness value is lower than 0,33 . Another indicator investigated is the orthogonal quality value. The orthogonal quality value approaching 1 indicates that a better mesh structure has been obtained. In contrast, if the orthogonal quality value approaches 0 , the mesh structure deteriorates. The minimum orthogonal quality for all types of cells should be more than 0,01 , with a significantly higher average value. This study defined the minimum orthogonal quality as 0,06 , and the average orthogonal quality of 0,81 for the finite element simulations. As a result, it can be stated that the mesh structure is adequate for realistic results.
The outer surface of the trabecular and cortical layer is fixed to the working environment with the fixed contact model. The implant geometries are allowed to displace along the z-axis. The vertical load of $150 \mathrm{~N}, 200 \mathrm{~N}, 250 \mathrm{~N}$, and $300 \mathrm{~N}$ [12-14] is applied, respectively, to the top of all implant models placed in the right molar region as a distributed load. In the study, the stress distribution is represented as $\sigma_{v m}$ (von Mises Equivalent Stress). Based on the tension stress $\sigma_{t s}$ and the compression stress $\sigma_{c s}$, the equivalent von Mises stress value can be calculated as follows:

$\sigma_{v m}=\left(\sigma_{t s}^{2}+\sigma_{c s}^{2}-\sigma_{t s} \sigma_{c s}\right)^{0,5}$

Stress transfer parameter (STP), which can be expressed quantitatively to characterize the load-sharing between the implant and the bone, has been defined as nondimensional numbers. These dimensionless numbers play an important role in assessing the load-sharing between the implant and the surrounding bone. Thus, the effects of stress shielding in different groove geometries can be compared with these dimensionless numbers. 


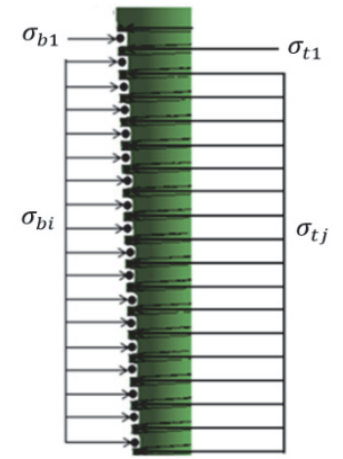

Figure 4 Implant geometry and definition of regions for calculating the average screw-thread stress values [16]

In the study by Gefen [16], the values taken along the implant shown in Fig. 4 are given as the average of the equivalent stresses. The $\sigma_{b i}$ and $\sigma_{t j}$ respectively, on the groove geometry, represent the stress values in the bone and on the screw groove geometries.

The STP is calculated by the effective mean stress values taken over, the trabecular and adjacent to surrounding bone, implant groove geometries. The following formulas define the ratio of the stress value in the bone to the stress value on the conical thread section during the loading time:

$$
\begin{aligned}
& S T P_{\alpha}=\frac{\sigma_{b 1}}{\sigma_{t 1}} \\
& S T P_{\beta}=\sum_{i=j=2}^{i=j=N} \frac{\sigma_{b i}}{\sigma_{t j}} \\
& S T P_{\text {Sum }}=S T P_{\alpha}+S T P_{\beta}
\end{aligned}
$$

In this formulation, $S T P_{\alpha}$ represents the transfer of stress to the peripheral bone through the first tooth. The $\sigma_{t 1}$ represents the mean stress value that is read on the first tooth. The $\sigma_{b 1}$ represents the average stress values that are read from the first bone region shown in Fig. 4 in the trabecular bone volume resisting the tensile strength surrounding the implant. The $S T P_{\beta}$ defines the total stress transfer from the second tooth to the peripheral bone through the entire other tooth segments. The $S T P_{\text {Sum }}$ represents the total value of the stress transfer on the peripheral bone through the first tooth and all the remaining teeth. Ideally, the stress transfer should be maximum between the bone and the implant. The low $S T P_{\alpha}$ and $S T P_{\beta}$ ratios indicate that stress transfer is also low [16]. This may cause bone loss in the surrounding bone.

Table 1 Material properties defined for each geometry

\begin{tabular}{|c|c|c|c|c|}
\hline Properties & Unit & $\begin{array}{c}\text { Titanium } \\
\text { Implant (Ti- } \\
\text { 6Al-4V) }\end{array}$ & $\begin{array}{c}\text { Trabecular } \\
\text { Bone }\end{array}$ & $\begin{array}{c}\text { Cortical } \\
\text { Bone }\end{array}$ \\
\hline $\begin{array}{c}\text { Young's } \\
\text { Modulus }\end{array}$ & $\mathrm{GPa}$ & 105 & 1 & 20 \\
\hline $\begin{array}{c}\text { Poisson } \\
\text { Ratio }\end{array}$ & 0,35 & 0,35 & 0,35 \\
\hline
\end{tabular}

Local anisotropy on bone tissue has been previously described in the literature $[22,31,32]$. It is also known that the linear isotropic identification of bone tissue material showed a decrease in stress-strain values in bone tissue
[31]. In this study, Ti-6Al-4V titanium alloy is used as the implant material. Besides, isotropic, homogeneous, and linear elastic material is defined for the implant, trabecular bone, and cortical bone, as presented in Tab. 1 [17].

\section{RESULTS AND DISCUSSION}

Numerical 3D finite element simulations were performed for different loading conditions $(150 \mathrm{~N}, 200 \mathrm{~N}$, $250 \mathrm{~N}$, and $300 \mathrm{~N}$ ), considering patient diversity. In this regard, the effects of four different groove geometries (rectangular, symmetrical, reverse buttressed, and buttressed) on stress distribution and stress transfer were investigated comparatively. The obtained findings are presented by dividing them into two groups for effective comparison and interpretation. First, the effects of different groove profiles on stress distribution and stress transfer under $150 \mathrm{~N}$ loading were examined, and the results were interpreted. Then, the findings obtained for $200 \mathrm{~N}, 250 \mathrm{~N}$, and $300 \mathrm{~N}$ loading conditions are presented with tables, and the results are compared among themselves.

It is observed that the maximum stress value of all implants under the $150 \mathrm{~N}$ force is in the regions close to the last tooth (Fig. 5). It can be stated that the groove geometry affects the equivalent stress value that occurred on the implant. The lowest equivalent stress value is observed on the rectangular profile implant with $40,99 \mathrm{MPa}$ (Fig. 5a). The highest equivalent stress value of $46,77 \mathrm{MPa}$ is observed on the implant with the buttressed groove geometry (Fig. 5d). It is obtained that the equivalent stresses in implants with symmetric and reverse buttressed groove geometry are 43,80 $\mathrm{MPa}$ and 42,57 $\mathrm{MPa}$, respectively. There is no significant difference between these two groove geometries. It is noticed that the highstress values on the implants are in the last tooth regions where there is sharp rotation in the geometry.

Lee et al. [24] developed nine different thread designs considering the thread shape and taper. The geometric and mechanical effects of the symmetric, square, and buttressed profiles on marginal bone were evaluated numerically. The square profile was found to have the largest contact area. As a result, the lowest equivalent stress was obtained for the square profile under each condition determined. This study similarly obtained the lowest equivalent stress in the rectangular groove geometry with the largest contact area (Fig. 2 and Fig. 5).

As shown in Fig. 5, the equivalent stress densities on implants are observed to be distributed along the tooth portion that contacts the trabecular bone because of contact with the surrounding bone, the tooth region away from the shaft body of the screw. Besides, the stress value increases from the first tooth to the last tooth in all implant designs. This result is due to the fixed boundary condition defined in the interface. These values are the mean stress values taken from the outermost line of the groove geometry to the centre of the screw at a distance of $0,1 \mathrm{~mm}$.

This study calculated the average equivalent stress values from the first tooth to the last tooth over the entire tooth section (Fig. 6) for the different groove geometries. In Fig. 6a, the measurement points on the implant having the rectangular groove geometry are presented. Besides, the measured values are given for all groove geometries in Fig. 6b. 


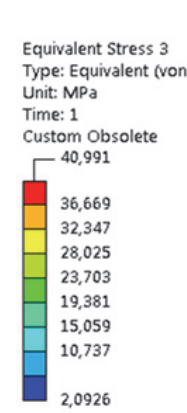

2,0926

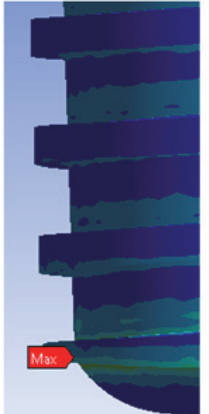

(a)

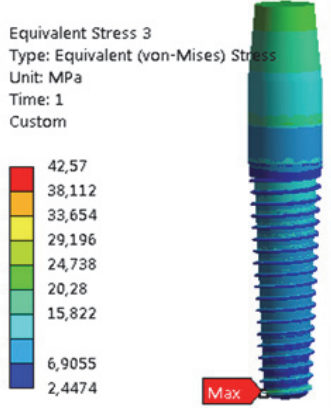

(c)
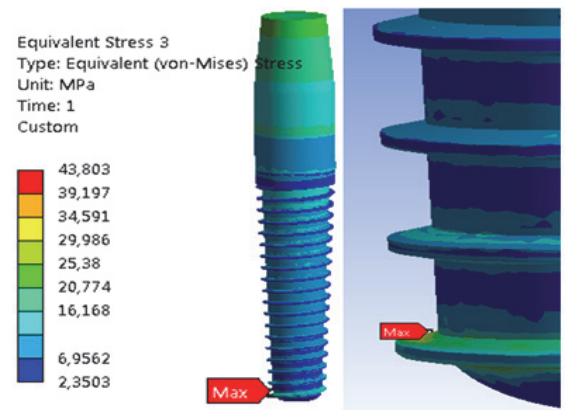

(b)

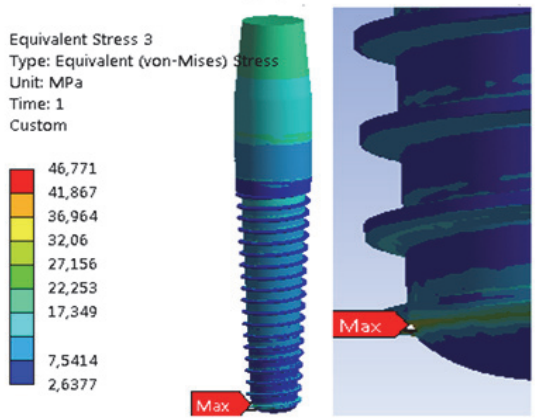

(d)

Figure 5 Equivalent stress distributions on implant models due to groove geometries (a) Rectangular, (b) Symmetrical, (c) Reverse Buttressed, and (d) Buttressed

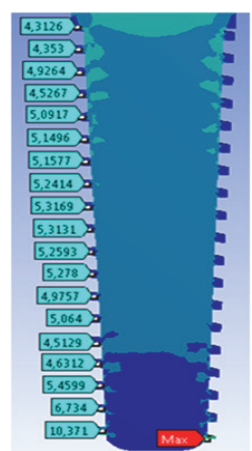

(a)

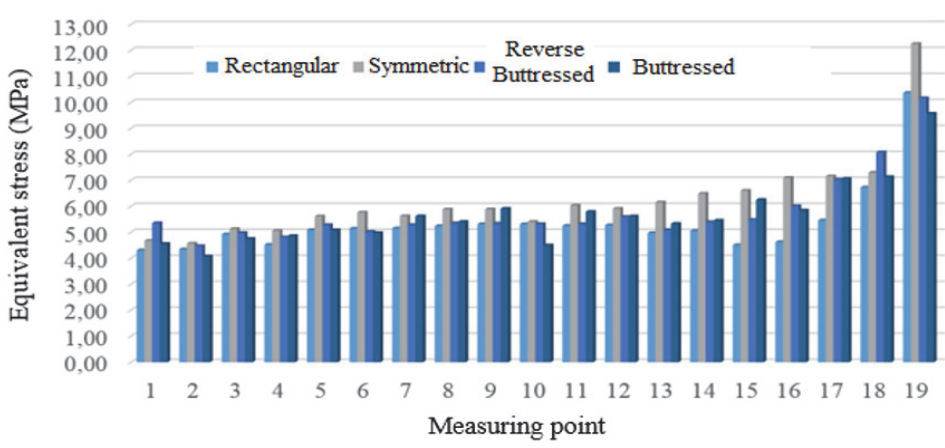

(b)

Figure 6 (a) Equivalent stress values at determined points on the rectangular profile, (b) graph of measured stress distributions on the implant due to groove geometries

The equivalent stress distributions in the cortical bone region under a tensile force of $150 \mathrm{~N}$ for the different groove geometries are given in Fig. 7. The lowest average equivalent stress value is $29 \mathrm{MPa}$ on the cortical bone with the buttressed groove geometry (Fig. 7). However, this value is obtained to be about $33 \mathrm{MPa}$ in the other three groove geometries.

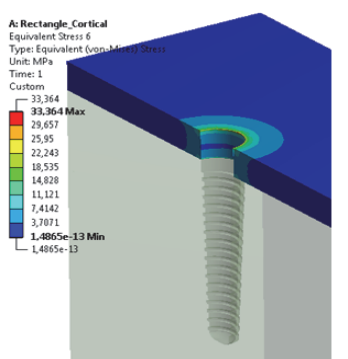

(a)

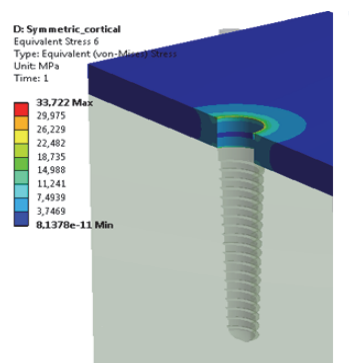

(b)

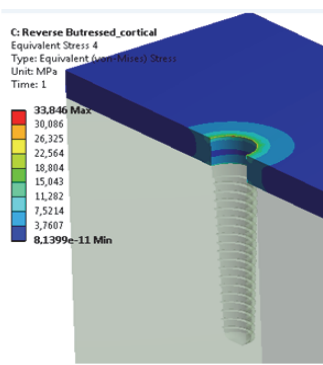

(c)

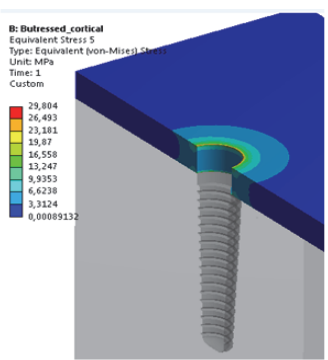

(d)

Figure 7 Equivalent stress distributions on the cortical bone regions due to groove geometries (a) Rectangular, (b) Symmetrical, (c) Reverse Buttressed, and (d) Buttressed

When the results are examined, it is observed that the maximum equivalent stress values on implants are at the lowest tooth region due to the groove geometry. Equivalent stress values on the trabecular bone are given in Fig. 8. The highest stress values are observed in the region surrounding the implant (Fig. 8). The maximum equivalent stresses are very close to each other. The stress increases in the last tooth proportional to the stress distribution on the implant. The highest equivalent stress value is observed in the bone area of the implant with symmetric groove geometry, while the lowest equivalent stress value is observed in the trabecular bone region of the implant with rectangular groove geometry. 


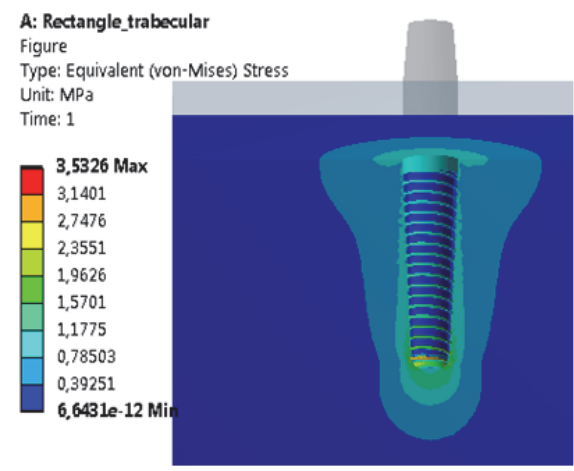

(a)

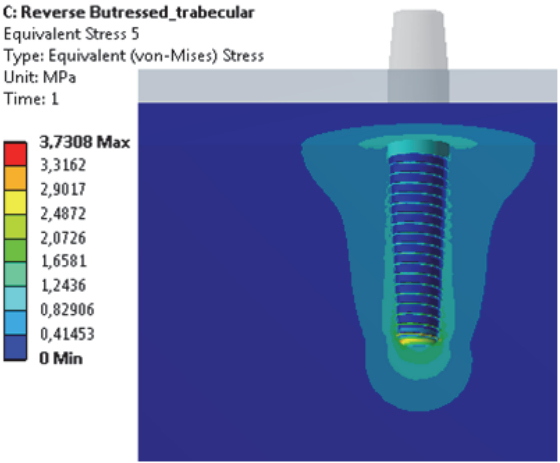

(c)

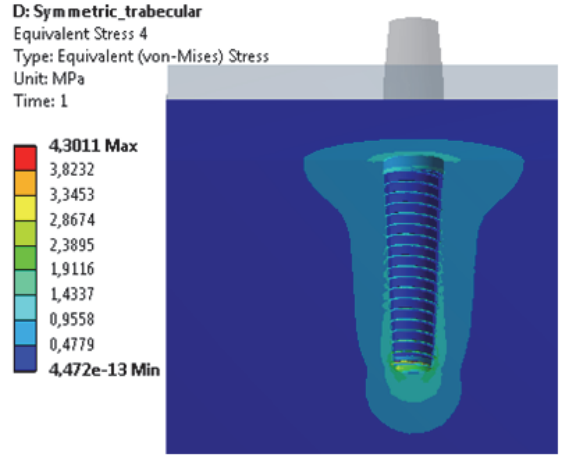

(b)

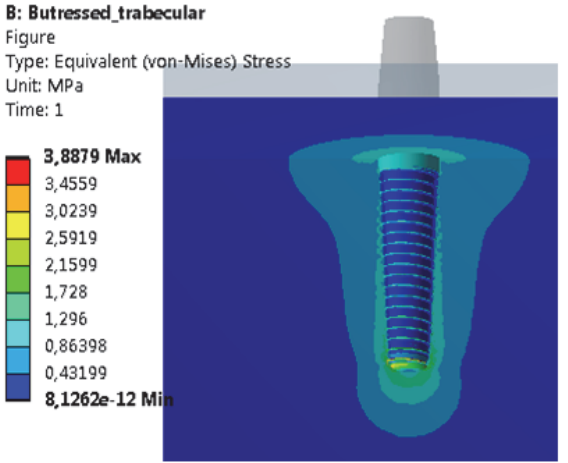

(d)

Figure 8 Equivalent stress distributions on the trabecular bone regions due to groove geometries (a) Rectangular, (b) Symmetrical, (c) Reverse Buttressed, and (d) Buttressed

Oswal et al. [33] designed implants with symmetrical, buttressed, and reverse buttressed geometries. The implants were placed in the molar region, and the $3 \mathrm{D}$ finite element simulations were performed. The stresses on cortical and trabecular bone and the implant were examined, respectively, and the results were compared among themselves. The symmetrical profile was found to be caused higher stress on the trabecular bone compared to the buttressed and reverse buttressed thread models. Eraslan and İnan [34] examined the influence of four thread configurations on the stress distribution. A greater stress concentration was found at the cortical bone layer compared to the trabecular bone layer. $\mathrm{Wu}$ et al. [28] performed both in vitro strain gauge tests and $3 \mathrm{D}$ finite element analysis to investigate the biomechanical effects of the implant designs. Implant designs were compared for three types of loading conditions. It was observed that the peak von Mises stress in the cortical bone was considerably higher than in the trabecular bone for all conditions. These results support the current study [28, 33, 34].
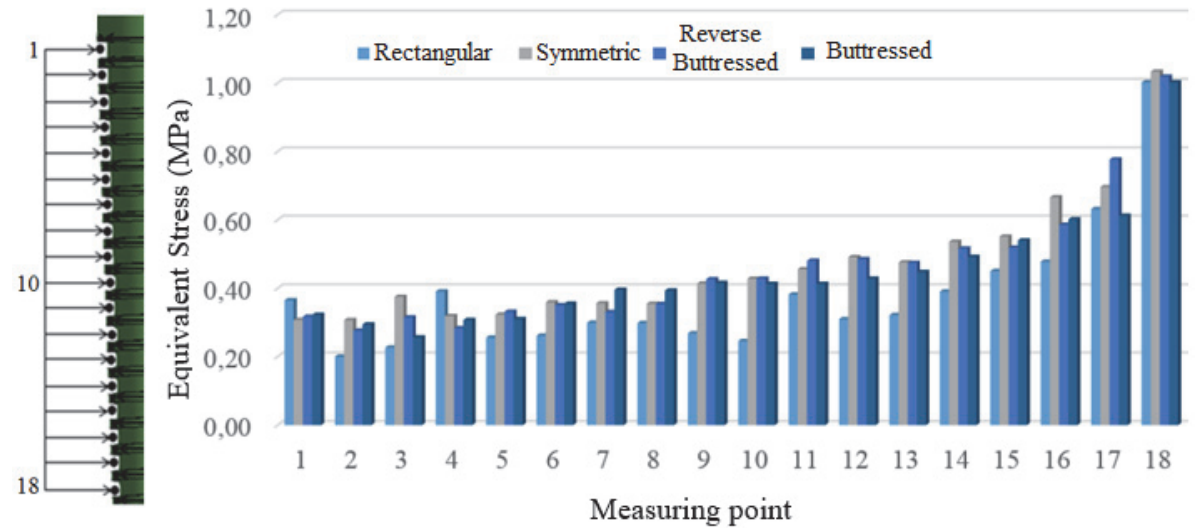

Figure 9 Bone-implant stress measurement points at the bone interface and graph of the measured stress distribution due to groove geometries

It is observed that the minimum stress values are in the bone adjacent to the implant body. The reason for this is the presence of a fixed contact interface between the implant groove geometries and the bone. This situation proves the existence of stress shielding $[16,17]$. The highrigidity titanium alloy implant carries a large part of the shared load, which results in a decrease in the equivalent stress in the adjacent bone regions. Fig. 9 presents the stress measurements on the trabecular bone layer and mean equivalent stress values obtained from the defined points. The average equivalent stress distribution measured between the trabecular bone and the groove geometry increases as the final tooth region is moved over the implant.

The higher STP allows for more stress transfer from the implant to the bone. Thus, the effects of possible and 
unwanted destructive stress shielding effects on the surrounding bone are reduced. It is known in the literature that the mechanical stimulus method is used to express the stress transferred from implant to bone $[16,17]$. The $S T P_{a}$ is calculated via Eq. (2), and the $S T P_{\text {Sum }}$, calculated via Eq. (4). The stress transfer on the surrounding bone through the first tooth region and the whole tooth portion $\left(S T P_{\alpha}\right.$ and $\left.S T P_{\text {Sum }}\right)$ for different groove geometries are presented in Fig. 10.

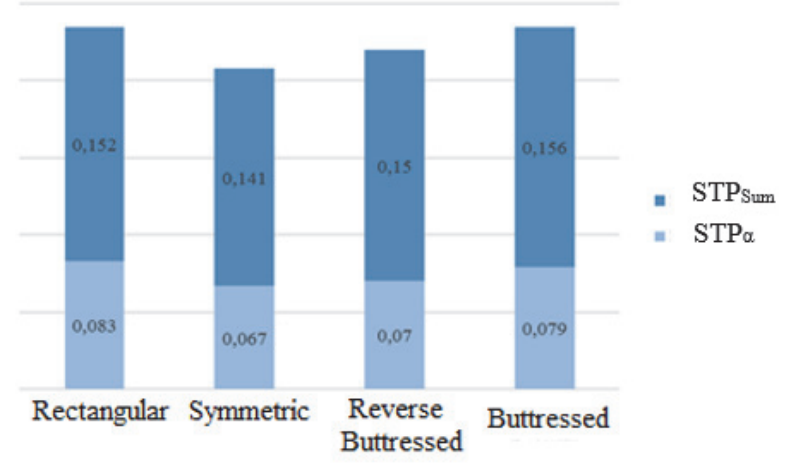

Figure 10 Stress transfer values from the first tooth region to the surrounding bone over the whole tooth portion

Tetteh and McCullough [35] investigated the effects of various thread designs on the stress transfer using the FEM. The influence of the square, trapezoidal, and buttressed profiles on stress transfer were compared and interpreted. It was indicated that stress transfer improved when the screw thread had a smaller contact area with the surrounding bone. Consequently, it was noted that a higher amount of stress could be transferred to the surrounding bone, with the buttressed profile having a higher stress distribution than the square thread profile. This study also found the highest stress transfer in buttressed design, where the highest equivalent stress occurred (Fig. 5 and Fig. 10). Hereby, it can be stated that the findings of the current study are consistent with the literature [24, 28, 33-35].

This study also investigated the stress distribution and stress transfer in small-diameter conical dental implants under the $200 \mathrm{~N}, 250 \mathrm{~N}$, and $300 \mathrm{~N}$ loading conditions in order to generalize the results obtained in accordance with the clinical point of view, considering patient diversity (i.e., age, gender, parafunctional habits, and anterior to posterior in the same mouth, etc.). In this regard, the equivalent stress distributions on the implant models, cortical bone, and the trabecular bone regions due to groove geometries were also examined for $200 \mathrm{~N}, 250 \mathrm{~N}$, and $300 \mathrm{~N}$ loading conditions, respectively. In this section, the results obtained for all loading conditions $(150 \mathrm{~N}, 200$ $\mathrm{N}, 250 \mathrm{~N}$, and $300 \mathrm{~N}$ ) are presented in tables. The findings were compared among themselves, and the results were interpreted.

Table 2 Maximum equivalent stress values on implant models due to groove geometries

\begin{tabular}{|c|c|c|c|c|}
\hline \multirow{2}{*}{$\begin{array}{c}\text { Loads } \\
\mathrm{N}\end{array}$} & \multicolumn{4}{|c|}{ Maximum Equivalent Stress Values Due to Groove } \\
Geometries / MPa \\
\cline { 2 - 5 } & Rectangular & Symmetric & $\begin{array}{c}\text { Reverse } \\
\text { Buttressed }\end{array}$ & Buttressed \\
\hline 150 & 40,991 & 43,803 & 42,570 & 46,771 \\
\hline 200 & 54,655 & 58,404 & 56,760 & 62,361 \\
\hline 250 & 68,318 & 73,005 & 70,950 & 77,952 \\
\hline 300 & 81,982 & 87,606 & 85,140 & 93,542 \\
\hline
\end{tabular}

Tab. 2 indicates the maximum equivalent stress values on the implant models according to groove geometries for all loading conditions. It was observed that the highest equivalent stress occurs in buttressed geometry for all conditions. In contrast, the lowest equivalent stress values were obtained in the rectangular geometry with the largest contact area (Fig. 2 and Tab. 2). It was found around a 3\% difference between the symmetric and reverse buttressed geometries under all loading conditions.

Moreover, the maximum equivalent stress values on the cortical bone region under the various loading conditions $(150 \mathrm{~N}, 200 \mathrm{~N}, 250 \mathrm{~N}$, and $300 \mathrm{~N})$ for the different groove geometries are given in Tab. 3. As a result, it was observed that the buttressed groove geometry causes the lowest stress values in the cortical bone region for all loading conditions. The stress values occurred by the rectangular, symmetrical, and reverse buttressed groove geometries on the cortical bone regions found to be close. In this regard, it can be stated that the buttressed profile showed superior performance in terms of equivalent stress distributions on the cortical bone regions.

Table 3 Maximum equivalent stress values on the cortical bone regions due to groove geometries

\begin{tabular}{|c|c|c|c|c|}
\hline \multirow{2}{*}{$\begin{array}{c}\text { Loads } \\
\mathrm{N}\end{array}$} & \multicolumn{4}{|c|}{ Maximum Equivalent Stress Values Due to Groove } \\
Geometries / MPa
\end{tabular}

Table 4 Maximum equivalent stress values on the trabecular bone regions due to groove geometries

\begin{tabular}{|c|c|c|c|c|}
\hline \multirow{2}{*}{$\begin{array}{l}\text { Loads / } \\
\qquad \mathrm{N}\end{array}$} & \multicolumn{4}{|c|}{$\begin{array}{l}\text { Maximum Equivalent Stress Values Due to Groove } \\
\text { Geometries / } \mathrm{MPa}\end{array}$} \\
\hline & Rectangular & Symmetric & $\begin{array}{c}\text { Reverse } \\
\text { Buttressed }\end{array}$ & Buttressed \\
\hline 150 & 3,532 & 4,301 & 3,730 & 3,887 \\
\hline 200 & 4,710 & 5,734 & 4,974 & 5,183 \\
\hline 250 & 5,887 & 7,168 & 6,218 & 6,479 \\
\hline 300 & 7,065 & 8,602 & 7,461 & 7,775 \\
\hline
\end{tabular}

Tab. 4 shows the maximum stress values on the trabecular bone regions according to different groove geometries. It was determined that the symmetrical profile has the highest equivalent stress value for all loading conditions. A difference of approximately 10\% was observed between the stress values when the buttressed and the rectangular profiles were compared. This difference is around $4,2 \%$ for the buttressed, and the reverse buttressed groove geometries (Tab. 4). It can be easily seen from Tab. 3 and Tab. 4 that the stress that occurred in the cortical bone region is much higher than in the trabecular bone region.

Implant design is considered a vital criterion in stress transfer to the surrounding bone [28]. Bone regeneration in trabecular bone structures is known to be due to stress transmitted to the peripheral bone through the implant. Each increase in stresses in the peripheral bone promotes bone regeneration by distributing bone density. In contrast, the reduction in stresses leads to bone loss, thus loosening the implant and eliminating mechanical stability. Ideally, the stress transfer is expected to be $0,96-0,99$. However, this is when the two contacting materials have the same mechanical properties, and complete contact is provided. 
This study revealed that long-term implant stability might be dangerous since the stress transfer value for all different profiles was used in the range of $0,141-0,156$ for the small-diameter conical implants.

STP is considered as a mechanical stimulus model to promote bone regeneration in peripheral bone with different groove profiles under load. In the symmetric profile $\left(q_{1}=q_{2}=15^{\circ}\right)$, the lowest stress transfer to the surrounding bone with the total stress transfer of 0,141 is observed. Moreover, the maximum stress transfer with the total stress transfer of 0,156 is obtained for the buttressed profile $\left(q_{1}=5^{\circ}, q_{2}=20^{\circ}\right)$. In the literature, it has been reported that bone loss is the least around the first tooth. Thus, the reverse buttressed groove profile is reduced over the total tooth section to the surrounding bone. The buttressed groove profile decreased the stress transfer value of the first tooth section compared to the rectangular profile and increased the total stress transfer value from the first tooth to the last tooth. Hereby, it can be stated that stress transfer leads to a more uniform transfer of stress to the peripheral bone by reducing the condensation only in the first tooth region and increasing the stress transfer through the other tooth section.

The cortical bone provides much better support to the implants than the trabecular bone, and its rigidity is much better (Fig. 7 and Fig. 8). The cortical bone accommodates higher maximum equivalent stress zones than the trabecular bone according to the shape of the loading to which it is exposed. It is possible to reduce local high equivalent stress regions on the cortical bone by altering the shape of the implant groove profile. The results obtained from Fig. 7 show that the buttressed groove profile reduces the maximum equivalent stress value in the cortical bone by $11 \%$. This may lead to a reduction of the localized high maximum equivalent stress in the cortical bone and show that the surrounding trabecular bone with the buttressed groove profile results in more uniform and more stress transfer. It is known that the increase obtained in the stress transfer, according to Wolff's law [10], leads to an increase in bone mass by encouraging bone regeneration in the surrounding bone where the implant is adhered to and the long-term success in implant stability.

The high success rates of small-diameter implants continue to be reported [21]. Thus, the number of studies on finite element (FE) regarding dental implants, which allows investigating the stress-strain distributions is also increasing [22, 24, 34]. However, there are some limitations to this study. This study defined isotropic, homogeneous, and linear elastic material properties that cannot fully simulate living tissue. More accurate analyses can be conducted by considering the more realistic material properties, bone porosity, roughness of implant surface, and natural conditions. Future clinical studies are needed to evaluate the effect of thread profiles on stress distribution and stress transfer in small-diameter conical implants.

\section{CONCLUSION}

This study aimed to compare different groove geometries to determine the most suitable profile for longterm implant stabilization in small-diameter conical implants. As a result, it is observed that the findings obtained are consistent with the literature. It is seen that buttressed groove profiles caused an increase in the stress transfer to the surrounding bone by $7,80 \%$, according to the symmetrical profile. Therefore, it is obtained that optimum stresses that promote bone re-formation in the peripheral bone reach the surrounding bone and reduce the negative stress shielding effects caused by the difference in stiffness at the bone-implant interface. It is concluded that the most appropriate groove profile is the buttressed profile. This is due to the reduction of the maximum equivalent stress value on the cortical bone and increasing the stress transfer in small-diameter conical implants. The lowest maximum equivalent stress value is observed in the rectangular profile implant, while the equivalent stress values for all profiles are below the yield limit. No plastic deformation is observed in any area of the implant geometries under 150 $\mathrm{N}, 200 \mathrm{~N}, 250 \mathrm{~N}$, and $300 \mathrm{~N}$ loading conditions.

It is observed that the rectangular profiled groove geometries have a lower maximum equivalent stress value than the different groove geometries. In the design of the implant, it is found that the groove geometries should be considered in a way to minimize the effects of stress shielding in bone reconstruction and to allow the transfer of the stimulus required for bone reconstruction.

This study found the rectangular groove geometry as the most suitable profile in terms of stress distribution. Still, for the small-diameter conical implants, the buttressed groove geometry determined the most suitable profile to minimize the stress transfer and stress shielding effects. Compared to the buttressed profile, the rectangular profile implants are $2,57 \%$, the reverse buttressed implants are $3,39 \%$, and the symmetrical profile implants are allowed 11,5\% lower stress transfer. While the ideal stress transfer is expected to be between 0,96 and 0,99 , this ratio is less than $85-88 \%$, which compromises the long-term stabilization of small-diameter conical implants in the bone. This deviation from the ideal value in the stress transfer is due to the stress shielding effect.

\section{Acknowledgements}

This study has been partially supported under Grant No. MEV-2016-097. The author's acknowledgment of institutions of the Council of Higher Education in Turkey (YOK), Bursa Uludag University, and the University of Central Oklahoma.

\section{REFERENCES}

[1] Creugers, N. H. J., Kreulen, C. M., Snoek, P. A., \& Kanter R. J. A. M. (2000). A systematic review of single-tooth restorations supported by implants. Journal of Dentistry, 28(4), 209-217. https://doi.org/10.1016/s0736-5748(99)00078-7

[2] Porter, J. A. \& Fraunhofer, J. A. (2005). Success or failure of dental implants? A literature review with treatment considerations. General Dentistry, 53(6), 423-432.

[3] Branemark, P. I. (1983). Osseointegration and its experimental background. The Journal of Prosthetic Dentistry, 50(3), 399-410. https://doi.org/10.1016/s0022-3913(83)80101-2

[4] Mavrogenis, A., Dimitriou, R., Parvizi, J., \& Babis, G. (2009). Biology of implant osseointegration. Journal of Musculoskeletal \& Neuronal Interactions, 9(2), 61-71. 
[5] Jokstad, A., Braegger, U., Brunski, J. B., Carr, A. B., Naert, I., \& Wennerberg, A. (2004). Quality of dental implants. International Dental Journal, 53(6 Suppl 2), 409-443. https://doi.org/10.1111/j.1875-595x.2003.tb00918.x

[6] Puleo, D. A. \& Thomas, M. V. (2006). Implant surfaces. DentalClinics of North America, 50(3), 323-38. https://doi.org/10.1016/j.cden.2006.03.001

[7] Abuhussein, H., Pagni, G., Rebaudi, A., \& Wang, H. (2010). The effect of thread pattern upon implant osseointegration. Clinical Oral Implant Research, 21(2), 129-136. https://doi.org/10.1111/j.1600-0501.2009.01800.x

[8] Baggi, L., Cappelloni, I., Di Girolamo, M., Maceri, F., \& Vairo, G. (2008). The influence of implant diameter and length on stress distribution of osseointegrated implants related to crestal bone geometry: A three-dimensional finite element analysis. Journal of Prosthetic Dentistry, 100(6), 422-431. https://doi.org/10.1016/S0022-3913(08)60259-0

[9] Niinomi, M. \& Nakai, M. (2011). Titanium-based biomaterials for preventing stress shielding between implant devices and bone. International Journal of Biomaterials, 2011, 10. https://doi.org/10.1155/2011/836587

[10] Wolff, J. (1986). The law of bone remodeling. Berlin: Springer. https://doi.org/10.1007/978-3-642-71031-5

[11] Koc, D., Dogan, A., \& Bek, B. (2010). Bite force and influential factors on bite force measurements: A literature review. European Journal of Dentistry, 4(2), 223-232. https://doi.org/10.1055/s-0039-1697833

[12] Gavião, M. B. D., Raymundo, V. G., \& Rentes, A. M. (2007) Masticatory performance and bite force in children with primary dentition. Brazilian Oral Research, 21(2), 146-152. https://doi.org/10.1590/s1806-83242007000200009

[13] Palinkas, M., Nassar, M. S. P., Cecílio, F. A., Siéssere, S., Semprini, M., Machado-de-Sousa, J. P., Hallak, J. E. C., \& Regalo, S. C. H. (2010). Age and gender influence on maximal bite force and masticatory muscles thickness. Archives of Oral Biology, 55(10), 797-802. https://doi.org/10.1016/j.archoralbio.2010.06.016

[14] Sharanraj, V. \& Ramesha, C. M. (2016). Finite element analysis of Ti-6Al-4V ELI and alumina bio-inert material used in molar tooth dental implant applications. InterceramInternational Ceramic Review, 66, 90-94. https://doi.org/10.1007/BF03401204

[15] Misch, C. E. (2005). Dental implant prosthetics. Saint Louis, MO: Mosby.

[16] Gefen, A. (2002). Optimizing the biomechanical compatibility of orthopedic screws for bone fracture fixation. Medical Engineering \& Physics, 24(5), 337-347. https://doi.org/10.1016/s1350-4533(02)00027-9

[17] Haase, K. \& Rouhi, G. (2013). Prediction of stress shielding around an orthopedic screw: Using stress and strain energy density as mechanical stimuli. Computers in Biology \& Medicine, 43(11), 1748-1757. https://doi.org/10.1016/j.compbiomed.2013.07.032

[18] Al-Johany, S. S., Al Amri, M. D., Alsaeed, S., \& Alalola, B. (2017). Dental implant length and diameter: A proposed classification scheme. Journal of Prosthodontics, 26(3), 252260. https://doi.org/10.1111/jopr.12517

[19] Allum, S. R., Tomlinson, R.A., \& Joshi, R. (2008). The impact of loads on standard diameter, small diameter and mini implants: A comparative laboratory study. Clinical Oral Implants Research, 19(6), 553-559. https://doi.org/10.1111/j.1600-0501.2007.01395.x

[20] Albrektsson, T., Gottlow, J., Meirelles, L., Östman, P., Rocci, A., \& Sennerby, L. (2007). Survival of NobelDirect implants: An analysis of 550 consecutively placed implants at 18 different clinical centers. Clinical Implant Dentistry \& Related Research, 9(2), 65-70. https://doi.org/10.1111/j.1708-8208.2007.00054.x

[21] Maló, P. \& de Araújo Nobre, M. (2011). Implants (3.3 mm diameter) for the rehabilitation of edentulous posterior regions: A retrospective clinical study with up to 11 years of follow-up. Clinical Implant Dentistry \& Related Research, 13(2), 95-103. https://doi.org/10.1111/j.1708-8208.2009.00188.x

[22] Wu, A. Y., Hsu, J. T., Chee, W., Lin, Y. T., Fuh, L. J., \& Huang, H. L. (2016). Biomechanical evaluation of one-piece and two-piece small-diameter dental implants: In-vitro experimental and three-dimensional finite element analyses. Journal of Formosan MedicalAssociation, 115(9), 794-800. https://doi.org/10.1016/j.jfma.2016.01.002

[23] Balkin, B. E., Steflik, D. E., \& Naval, F. (2001). Mini-dental implant insertion with auto-advance technique for ongoing applications. Journal of Oral Implantology, 27(1), 32-37. https://doi.org/10.1563/15481336(2001)027<0032:MIIWTA>2.3.C0;2

[24] Lee, C. C., Lin, S. C., Kang, M. J., Wu, S. W., \& Fu, P. Y. (2010). Effects of implant threads on the contact area and stress distribution of marginal bone. Journal of Dental Sciences, 5(3), 156-165. https://doi.org/10.1016/S1991-7902(10)60023-2

[25] Davarpanah, M. D., Martinez, H., Kebir, M., Tecucianu, J., Lazzara, R. J., Celletti, R., Etienne, D., Jansen, C., \& Donath, K. (2003).Clinical manual of implant dentistry. London: Quintessence Publishing.

[26] Yang, J. \& Xiang, H. (2007). A three-dimensional finite element study on the biomechanical behavior of an FGBM dental implant in surrounding bone. Journal of Biomechanics, 40(11), 2377-2385. https://doi.org/10.1016/j.jbiomech.2006.11.019

[27] Nobel, B. (2015). Product catalog complete assortment 2015-2016. Retrieved from http://www.artisbiotech.ro/wpcontent/uploads/Catalog-de-produse-Nobel-Nou.pdf

[28] Wu, A. Y., Hsu, J. T., Fuh, L. J., \& Huang, H. L. (2020). Biomechanical effect of implant design on four implants supporting mandibular full-arch fixed dentures: In vitro test and finite element analysis. Journal of Formosan Medical Association, 119(10), 1514-1523. https://doi.org/10.1016/j.jfma.2019.12.001

[29] Jamadagni, H. G., Karaman, H., Karpat, F., Williams, W., Dhanasekaran, L., \& Khandaker, M. (2017). Effect of microgrooving on the stress shielding of titanium: Experimental and numerical investigations. Proceedings of the ASME 2017 International Mechanical Engineering Congress and Exposition, Tampa, FL, United States. https://doi.org/10.1115/IMECE2017-70946

[30] Ruggiero, A., D'Amato, R., \& Affatato, S. (2019). Comparison of meshing strategies in THR finite element modelling. Materials, 12, 1-11. https://doi.org/10.3390/ma12142332

[31] Hellmich, C., Kober, C., \& Erdmann, B. (2008). Micromechanics-based conversion of CT data into anisotropic elasticity tensors, applied to FE simulations of a mandible. Annals of Biomedical Engineering, 36(1), 108122. https://doi.org/10.1007/s10439-007-9393-8

[32] Bonnet, A. S., Postaire, M., \& Lipinski, P. (2009). Biomechanical study of mandible bone supporting a fourimplant retained bridge: Finite element analysis of the influence of bone anisotropy and foodstuff position. Medical Engineering \&Physics, 31(7), 806-815. https://doi.org/10.1016/j.medengphy.2009.03.004

[33] Oswal, M. M., Amasi, U. N., Oswal, M. S., \& Bhagat, A. S. (2016). Influence of three different implant thread designs on stress distribution: A three-dimensional finite element analysis. The Journal of Indian Prosthodontic Society, 16(4), 359-365. https://doi.org/10.4103/0972-4052.191283

[34] Eraslan, O. \& İnan, Ö. (2010). The effect of thread design on stress distribution in a solid screw implant: A 3D finite element analysis. Clinical Oral Investigations, 14(4), 411416. https://doi.org/10.1007/s00784-009-0305-1

[35] Tetteh, E. \& McCullough, M. B. A. (2020). Impact of screw thread shape on stress transfer in bone: A finite element 
study. Computer Methods in Biomechanics and Biomedical

Engineering, 23(9), 518-523.

https://doi.org/10.1080/10255842.2020.1743980

\section{Contact information:}

Onur Can KALAY, PhD. Candidate

Bursa Uludag University,

Department of Mechanical Engineering,

Bursa 16059, Turkey

E-mail: onurcankalay@uludag.edu.tr

Hasan KARAMAN, PhD. Candidate

Bursa Uludag University,

Department of Mechanical Engineering,

Bursa 16059, Turkey

E-mail: hasankaraman26@gmail.com

Fatih KARPAT, Full Professor

(Corresponding author)

Bursa Uludag University,

Department of Mechanical Engineering,

Bursa 16059, Turkey

E-mail: karpat@uludag.edu.tr

\section{Oğuz DOĞAN, PhD.}

Kahramanmaras Sutcu Imam University,

Department of Mechanical Engineering,

Kahramanmaras 46050, Turkey

E-mail: oguzdogan@ksu.edu.tr

Celalettin YÜCE, Assistant Professor

Bursa Technical University,

Department of Mechatronics Engineering,

Bursa 16310, TURKEY

E-mail: celalettin.yuce@btu.edu.tr

Esin KARPAT, Assistant Professor

Bursa Uludag University,

Department of Electrical and Electronics Engineering,

Bursa 16059, Turkey

E-mail: esinoz@uludag.edu.tr

Lokesh DHANASEKARAN, M.Sc.

University of Central Oklahoma,

Department of Engineering and Physics,

Edmond 73034, USA

E-mail: Idhanasekaran@uco.edu

Morshed KHANDAKER, Full Professor

University of Central Oklahoma,

Department of Engineering and Physics,

Edmond 73034, USA

E-mail:mkhandaker@uco.edu 